\title{
Investment Processes as the Foundation of Economic Growth
}

\author{
Arsen Azidovich Tatuev \\ Doctor of Economic Sciences, Professor, Russian Academy of National Economy and Public Administration Presidente Russian \\ Federation Russia, 357502, Stavropol region, Pyatigorsk, Dunaevsky st., 5 \\ Violetta Valerievna Rokotyanskaya \\ Candidate of economic sciences, associate professor, Moscow State University of \\ Food Production Russia, 125080, Moscow, Volokolamskoye sh., 11
}

\begin{abstract}
Alim Beslanovich Nagoev
Doctor of Economic Sciences, Professor, Kabardino-Balkarian State University Named After Kh.M. Berbekov Russia, 360004, Kabardino-Balkarian Republic, Nalchik, Chernyshevskogo st., 173
\end{abstract}

\section{Svetlana Anatolevna Nefedkina}

Candidate of Economic Sciences, Associate Professor, Sochi State University Russia, 354000, Krasnodar region, Sochi, Sovetskaya St., 26a

\section{Galina Vladimirovna Sarkisyants}

Candidate of economic sciences, associate professor, Rostov state economic University Russia, 357700, Stavropol Region, Kislovodsk, Dzerzhinskogo st., 22/24

Doi:10.5901/mjss.2015.v6n6p348

\section{Abstract}

The objective of the study is to identify the priority tendencies in the investment emerged in recent years in the industrial sector of the national economy as well as the main factors limiting the growth of industrial production. The results show that for both medium/large enterprises and small businesses of the industrial sector, the most negative are the same factors that impede the extension of production. Among the most important constraints are the lack of financial resources, high levels of taxation, lack of demand for the company's products in the domestic market, as well as the deterioration and lack of equipment and the economic uncertainties. The insufficient Russian financial market development and the unavailability of loan funds are associated with the most of the limiting factors. This means that a more efficient state economic and industrial policies are required.

Keywords: industry, investment, business confidence, industrial policy

\section{Introduction}

The post-industrial society's distinguishing features are rooted in the nature of the socio-economic relations, that promote a new interlinkage between material and non-material production. In this context, high technologies and manufacturing infrastructure are playing an increasingly important role, while the industrial sector itself forms the basis for reproduction which meets society's needs and sets the general development trajectories for non-material sectors in post-industrial economies.

New socio-economic relations are realized in such organization forms as integrated industrial entities (clusters, industrial parks), various models of interaction between the integrated entities (partnership, outsourcing etc.). The integrated entities' influence on competitive advantages (infrastructure, innovations, integration, full cycle of high added value products manufacturing) becomes stronger. 


\section{Literature Review}

The ongoing structural changes in developed and developing economies, as well as the sharpened competition within the processes of globalization and specialization, compel the scientists to focus on creation of economic organizational structures, allowing to increase the competitiveness of national industries and economic system as a whole (Zahmatov, 2012; Rokotyanskaya, Gerasimov \& Sarkisyants, 2015; Lenkovets \& Sinkov, 2014). It is natural that a lot of attention is given to the innovative development of industry, particularly in the context of the ongoing transformation of socioeconomic processes and formation of Russia's innovative potential (Edelev \& Lyapuntsova, 2014; Rybakov, 2011; Dokukina, 2014).

In addition, there is a considerable discussion on the issue related to the maintenance of national economic security in terms of deepening globalization processes (Arkin \& Vlassenko, 2011; Tatuev \& Tatuev, 2015).

But in general, especially from the viewpoint of the systemic approach, the investment is the key aspect of this issue (Nerovnya \& Khachirov, 2013; Kolmykova, Sitnikov \& Tretyakov, 2015). In this context, tax advantages for investors (Popov, 2012), and institutional factors (Shkrebela, 2012) are often discussed.

\section{Method}

We used the methods of time series with data graphic visualization, statistical groupings of industrial enterprises assessments regarding the investment objectives and the factors limiting investment activity, we also provide a comparison of a number of indicators across countries.

\section{Results}

4.1 Analysis of fixed capital investments in the Russian Federation (by industry sectors and in the economy as a whole)

However, the development of aggregate investment activity is of additional interest, especially since Russian economy has formed a whole set of negative factors in this regard.
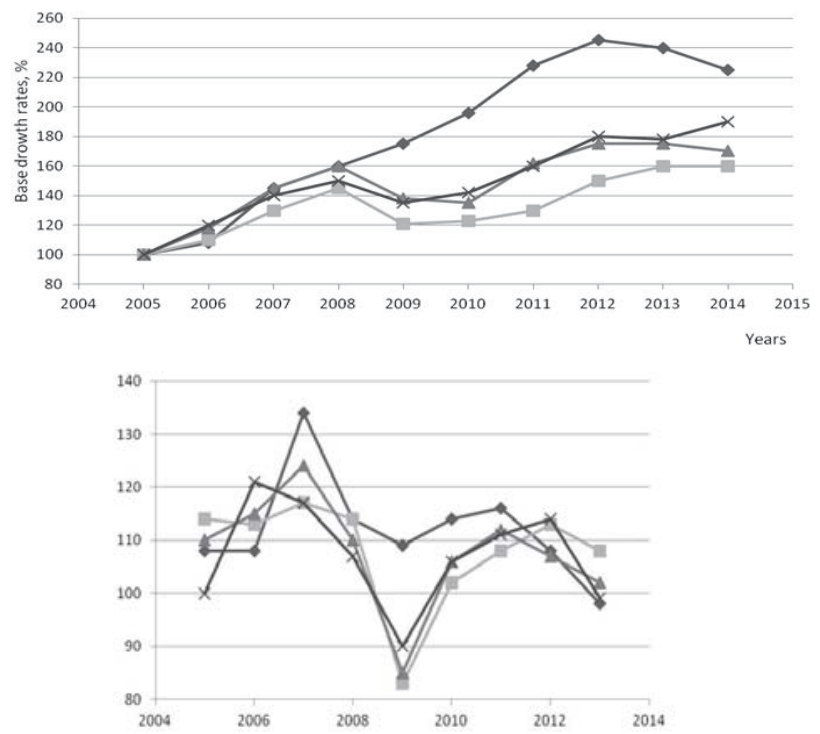

Figure 1. Dynamics of investments in fixed assets in Russian Federation by industry sectors and economy at large during the period from 2005 to 2014, in comparable prices (charts designed and built by the author based on the data: Official statistics: investment in non-financial assets // Federal state statistics service - URL: http://www.gks.ru/free_doc/ new_site/business/invest/Din-invOKVED.xls) 
Figure 1 illustrates the dynamics of investments in fixed assets in Russian Federation by industry sectors and economy at large during the period from 2005 to 2014. The data are given in comparable prices. Analyzing the investments basic growth rate we should notice that investments in fixed assets (in economy as a whole) has increased by $70,4 \%$ during the period in question. In mining, the increase was more significant - by $88,4 \%$. Investment growth rates in manufacturing were slightly lower than those of the economy as a whole - $60,7 \%$. At the same time investment in electricity, gas and water production and distribution more than doubled and was around $224,5 \%$.

If we analyze chain growth rates of investment in fixed assets, it becomes obvious that in recent years its dynamics has slowed in general or in specific sectors. The chart shows that the slowdown peaked in crisis years (2008-2009). Thus, if in 2006-2007 the annual rate of investment in fixed assets growth in economy and in specific industrial sectors was at the level of 10-30\%, in 2010-2013 the annual the growth rate decreased to 0-10\%. In 2014, in the economy and in particular industries, with the exception of the mining sector, a negative growth of investments was shown compared with 2013.

\subsection{Distribution of industrial enterprises by objectives and priorities of investment in fixed assets}

Figure 2 is a diagram illustrating the priority areas for investment in fixed assets by Russian industrial enterprises in 2013. Data were obtained from sample surveys of enterprises investment activity conducted by the Service of State Statistics of Russia. The diagram shows that almost three quarters of surveyed enterprises named replacement of physically worn equipment and machinery as the main aim for fixed capital investment.

Almost half of the respondents noted such areas as automation of the existing production process, environmental protection and energy saving as their priorities in investment. Slightly less than half - $46 \%$ - prioritized the investment in new production technology introduction; $38 \%$ of respondents identified as key priorities the reduction of production costs and an increase in production capacity in addition to expansion of the product range.

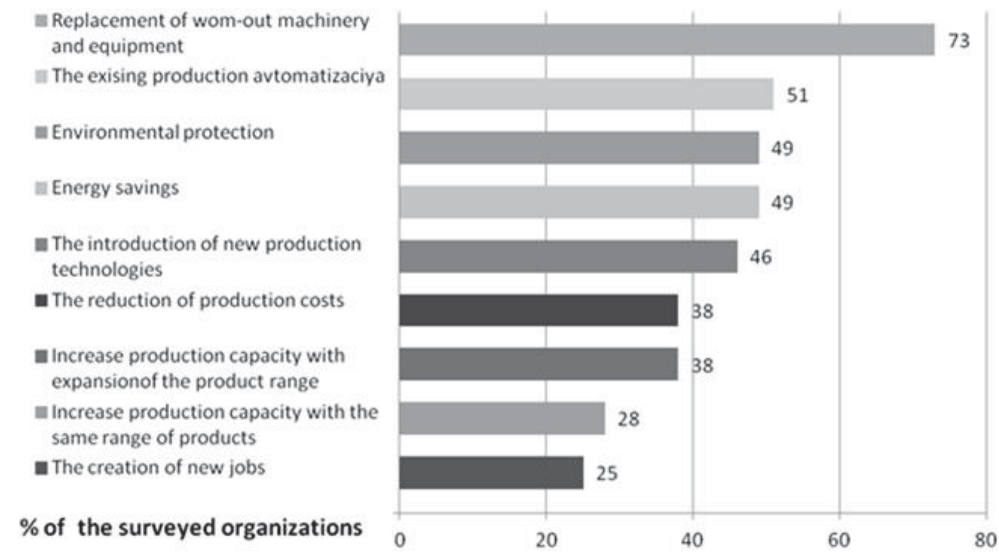

Figure 2. Distribution of industrial enterprises by objectives and priorities in fixed capital investment in 2013 , in $\%$ of surveyed enterprises (charted by the author on the basis of: Industry of Russia. 2014: Statistical Yearbook. - M .: Rosstat, 2014. - p.121).

However, the increase in production capacity while maintaining the same range of products was highlighted only by $28 \%$ of surveyed enterprises. Another $25 \%$ of respondents focused on job creation.

Thus, it may be noted that among the key objectives of the investment in fixed assets in the industrial sector are those that are directly or indirectly aimed at improving the existing production efficiency. Lower priority is given to increasing the production capacity, and job creation is the least often mentioned by the surveyed enterprises. 


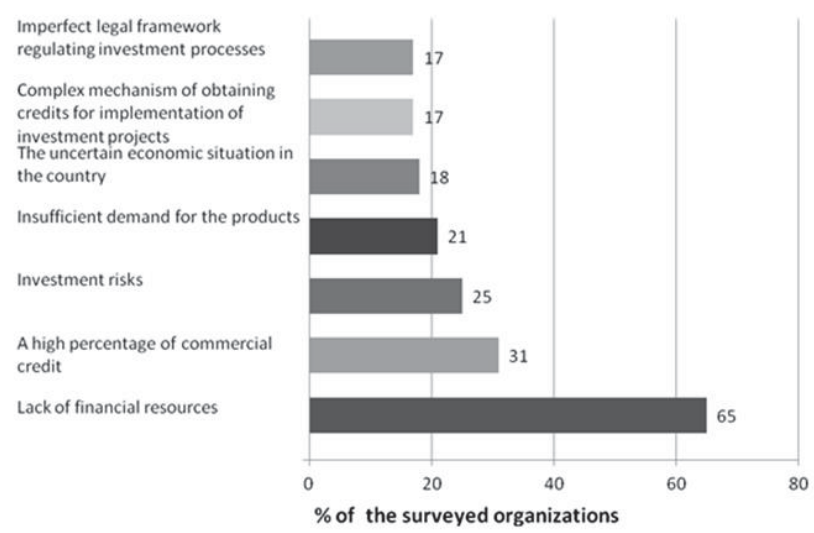

Figure 3. Assessment of constraints to industrial enterprises investment activity in 2013, in $\%$ of surveyed enterprises (diagram is drawn up by the author based on: Industry of Russia. 2014: Statistical Yearbook. - M .. Rosstat, 2014. p.122)

Figure 3 is a diagram illustrating the assessment constraints weighing on investment activity of industrial enterprises in different sectors of Russian economy in 2013. The diagram shows that about $2 / 3$ of the respondents (65\%) consider the shortage of own financial funds as the main limiting factor. Significantly fewer respondents noted such factors as the high interest rates (31\%) and investment risk (25\%). The other factors: lack of demand for products, the uncertainty of the economic situation in the country, a sophisticated scheme of obtaining loans for investment projects, an inadequate legal framework regulating investment processes, - are noted by 21 to $17 \%$ of respondents.

\subsection{Central banks base interest rates and inflation rates in the countries with high GVA economies}

As can be seen, one of the most important factors limiting investment activities and competitive advantages of Russian enterprises, is the question of funds availability. This factor also undermines the ability of the enterprise to enter the securities market. In particular, the existing requirements to the issuer and the listing procedure make this method of borrowing impossible for small and medium-sized enterprises. In addition, this kind of borrowing remains expensive. (Rodionov \& Pashkov, 2012) The level of real interest rates on such loans in Russia is significantly higher than in the US or Europe. (Kheifetz, 2012)

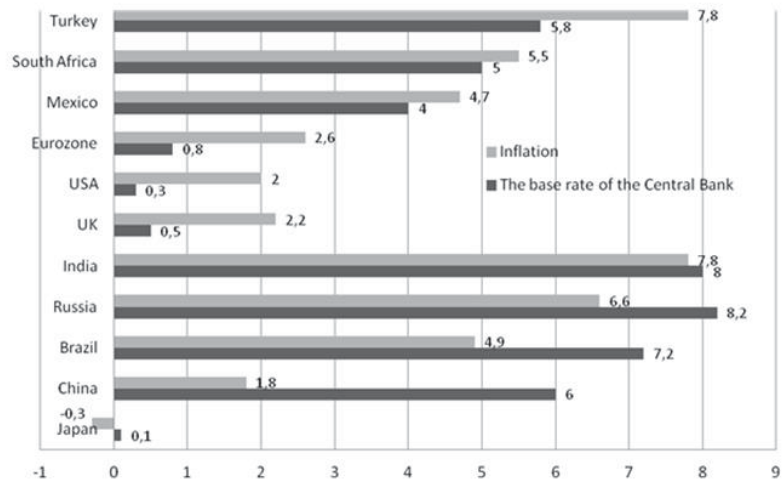

Figure 4. Central banks base interest rates and inflation rates in the countries with high GVA industries, 2012, in \% (charted by the author based on: Russia - one of the countries with really positive central bank interest rates // Expert Online. - URL: http://expert.ru/expert/2012/47/myi-nichego-ne-proizvodim/media/170798 
Thus, the relatively high level of the Russian financial market development and the availability of loan funds do not form competitive advantages of the country's economy, but on the contrary, adversely affect the existing ones. This situation is also characteristic to a number of other emerging market economies (Figure 4). In turn, the lack of long-term funds and underutilization of the resources represent an artificial brake for the economic growth and impede the achievement of significant success in international competition and specialization, since the deficit of long-term funds limits investment in the real economic sector, and, therefore, has a negative impact on business confidence. This is especially evident with regard to the level of business mobility and initiatives in new kinds of products manufacturing.

\subsection{Assessments of the main factors limiting the increase in production in the industrial sector of Russian economy}

Figure 5 illustrates the distribution of assessments made by enterprises of industrial sector (excluding small businesses) regarding the main factors limiting the increase in production in 2013. The diagram shows that in general, enterprises of all industrial sectors considered as the most negative factors the lack of funding; high level of taxation; an insufficient demand for the company's products in the domestic market; poor condition and lack of equipment; uncertainty concerning the economic situation in the country. These factors have been noted by $28.3-42.5 \%$ of respondents. In mining, the most severe factor limiting the increase in production was the high level of taxation, which was highlighted by $39.3 \%$ of the respondents. However, the importance of this factor has slightly declined over the last 2-3 years.

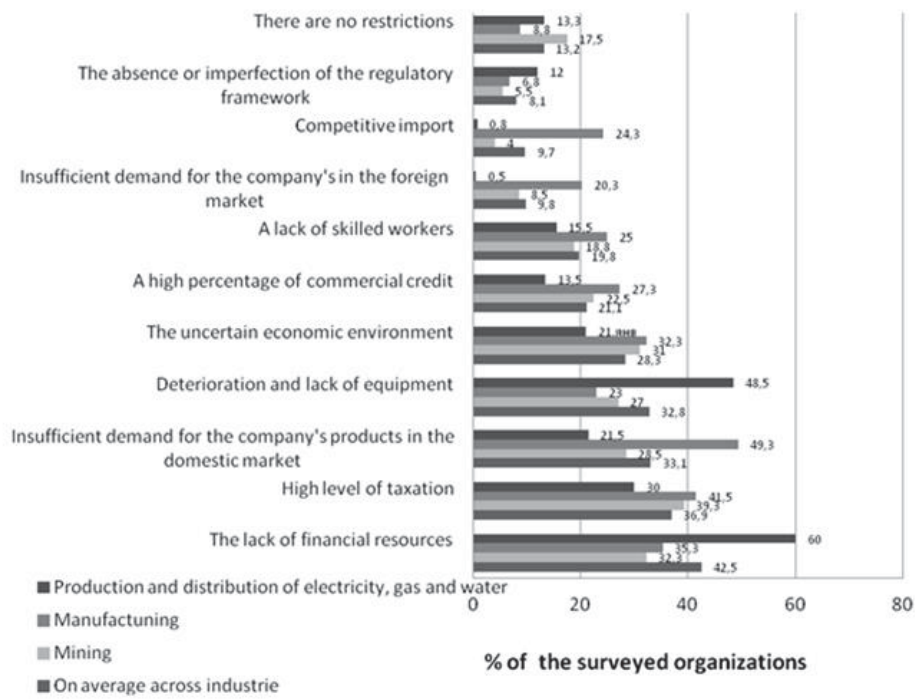

Figure 5. Distribution of assessments regarding the main factors limiting the increase in production by enterprises of industrial sector of Russian economy (excluding small businesses) in 2013. in \% of surveyed enterprises (charted by the author based on: Industry of Russia. 2014: Statistical Yearbook. - M .: Rosstat, 2014. - p.60-62)

In manufacturing industries, the high taxes and lack of demand for the products in the domestic market were identified as the major constraining factors (41.5 and $49.3 \%$ of respondents, respectively). Moreover, if the influence of the first factor in the last 2-3 years has significantly reduced, the effect of the second factor remained relatively static. 


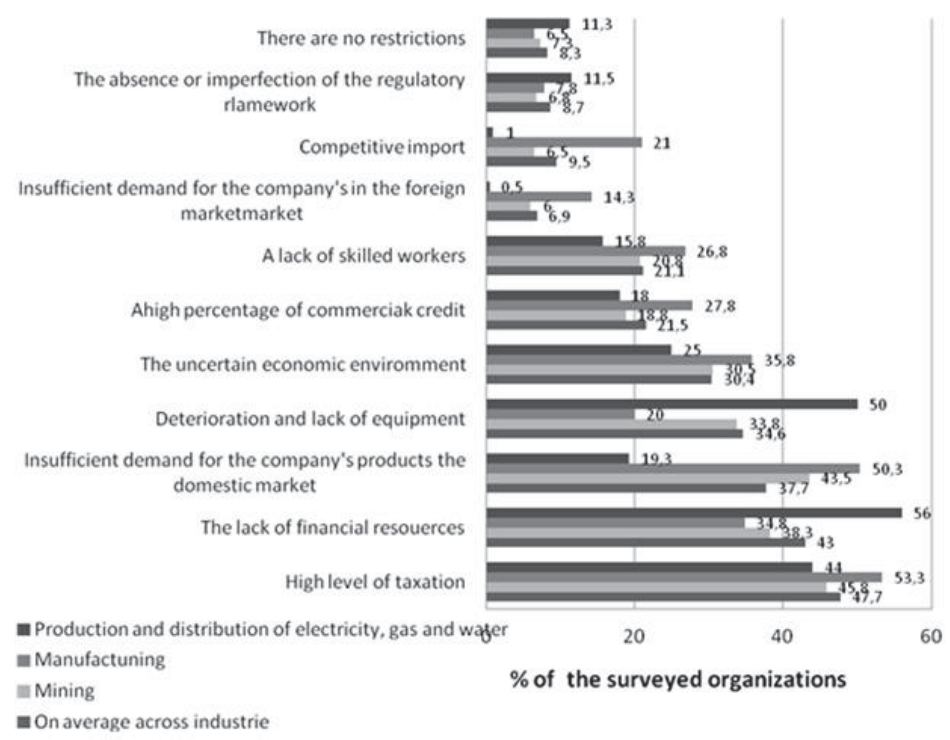

Figure 6. Distribution of assessments regarding the main factors limiting the increase in production by industrial enterprises of of Russian economy (excluding small businesses) in 2013. in \% of surveyed enterprises (charted by the author based on: Industry of Russia. 2014: Statistical Yearbook. - M .: Rosstat, 2014. - p.94-95)

The generating business noted that the lack of funding, poor condition and lack of equipment acted as the most important deterrent ( 60.0 and $48.5 \%$ of respondents, respectively). The relevance of these factors has slightly declined over the past 2-3 years.

It is also noteworthy that other factors restricting the growth of production have shown some decline, and this decline was more dynamic than the decrease of above-listed factors significance. This suggests that the unfavorable situation in addressing issues limiting the production development of in the medium and large enterprises of the industrial sector has not significantly changed.

Figure 6 is a diagram illustrating the distribution of assessments given by the small businesses in industry regarding the major factors limiting the growth of production in 2013. Among them, as shown in Figure 6, the most of all sectors enterprises named the high level of taxation; lack of financial resources; insufficient demand for the company's products in the domestic market; deterioration and lack of equipment; the Russian economy uncertainties. These are the same factors that were identified as major constraints by the medium and large industrial enterprises, and in general, they were mentioned by 30.4 to $47.7 \%$ of small businesses, somewhat more than in the case of medium and large enterprises.

In mining, the high level of taxation; lack of financial resources; insufficient demand for the company's products in the domestic market cause the greater damage to the production development. It has been noted by 38.3 to $45.8 \%$ of respondents. The pertinence of the first two factors over the past 2-3 years has slightly declined, while the relevance of the latter - the lack of demand for the company's products in the domestic market - has increased. Manufacturing enterprises identified as the most critical high taxes and lack of demand for the products in the domestic market - 53.3 and $50.3 \%$ of respondents, respectively. Moreover, if the influence of the first factor has significantly reduced during the last 2-3 years, the effect of the second factor has remained unchanged. The most acute factors for generating small businesses were high taxes and lack of funds, as well as the deterioration and lack of equipment. These were noted by $44.0-56.0 \%$ of respondents. The lack of funds has been slightly less important in the last 2-3 years, while the relevance of the remaining two factors has not changed.

As for other factors limiting the growth of production in industrial sector small businesses, the dynamics was multidirectional - some of them have reduced their relevance, others, on the contrary, have increased it. In general, this process has demonstrated no sign of uniformity.

In general, it can be noted that in the industrial sector both medium / large enterprises and small businesses have 
noted as the most negative the same constraints to production development. Among them, again, there are: lack of financial resources; high level of taxation; insufficient demand for the company's products in the domestic market, as well as the deterioration and lack of equipment and uncertainty of the economic situation in Russia.

The most of the limiting factors are due to the insufficient development of financial market and the unavailability of funds in Russia. This means that a more efficient state economic and industrial policy is needed in investment.

\section{Discussion}

Scientific literature suggests a number of approaches to industrial policy. As a rule, industrial policy is a system of goals, objectives and instruments of public authorities and other market participants, who have a significant influence on decisions concerning the allocation of limited productive resources in order to ensure the prioritized development of the industry. (Aliev, 2000) At the same time, increasing attention is paid to the problems of increasing industrial development stability. (Tatuev, 2014) In addition, many studies take into account that in developed economies the government role is not to be expanded, but to identify goals, objectives and priorities. (Andrianov, 2013) At the same time, close attention should be paid to the experience of Latin American countries where the liberal industrial policy was responsible for the slowdown of economic growth. (Romanova \& Bukhvalov, 2014) In recent times, the incentives for innovation activity in the economy have shown their increasing efficiency (Kuzmina, 2011; Borodin, Tatuev, Shash, Lyapuntsov \&, Rokotyanskaya, 2015).

\section{Conclusions}

However, since the Russian economy has formed serious constraints to the industrial development, one of priority objectives of the requirements specified by the Federal Law of 31.12.2014 №488-FZ "On industrial policy in the Russian Federation" implementation, should be to overcome these constraints. In our opinion, it may be achieved through the support of vertical industrial clusters creation, regrouping a number of industrial enterprises according to their industry sector, and peripheral enterprises vertically integrated with them. These integrated structures should assure a targeted and effective application of measures concerning the lack of funds, a high level of taxation and the lack of domestic demand for manufactured products. Only this kind of integrated economic space the State could and should play a key role through the mechanisms of public-private partnerships. As a part of state industrial policy it proposed to prioritize the creation of vertical industrial clusters, integrating similar enterprises grouped by industry. These integrated structures should assure a targeted and effective application of measures concerning the lack of funds and a high level of taxation. Only this kind of integrated economic space the State could and should play a key role through the mechanisms of publicprivate partnerships.

\section{References}

Zahmatov, V.Y. (2012). Clustering as an innovative form of economic systems development and an increase of the economy competitiveness. (pp. 25-30). Kazan Economic Bulletin. №1.

Rokotyanskaya, V.V., Gerasimov, A.N. \& Sarkisyants, G.V. (2015). Trends in innovative socio-economic development of Russian industry. (pp. 204-208). Economics, Statistics and Informatics. Bulletin of UMO. №3.

Lenkovets, O.M. \& Sinkov, L.P. (2014). Investing in human capital as a factor of increasing the competitiveness of Russian economy in the framework of sustainable development. (pp. 55-58). Problems of modern economy. №1 (49).

Edelev, D.A. \& Lyapuntsova, E.V. (2014). Innovative factors of Russian industry socio-economic development (pp. 250-255). Bulletin of the North Ossetian State University named after Costa Levanovich Khetagurov. № 4.

Rybakov, F.F. (2011). Industrial policy: innovation and investment components (pp. 77-82). Innovations. №2.

Dokukina, E.V. (2014). The investment component in the Russia's innovative potential development (pp. 43-48). Problems of regional economy. Vol.18. №1.

Arkin, P.A. \& Vlassenko, M.N. (2012). Economic globalization and the problems of national and international security. (pp. 101-105). Problems of modern economy. №1 (41).

Tatuev, A.A. \& Tatuev, Ask.A. (2015). Factors of economic security in business and in industry in present conditions. (pp. 900-903). Economy and entrepreneurship. Vol.1. № 6.

Nerovnya, T..N. \& Khachirov, A.D. (2013). Evaluation of the industrial investment multiplier effect. (pp. 28-34). Terra Economicus. Vol.11. №1-3.

Kolmykova, T.S., Sitnikov, E.V. \& Tretyakov, I.N. (2015). Credit resources in meeting the challenges of national economy modernization. (pp. 2-11). Finance and Credit. №14 (638).

Popov, M.V. (2012). Fiscal instruments to stimulate investment in innovative economic development. (pp. 208-218). Problems of 
modern science and practice. University named after V.I. Vernadsky. №2.

Shkrebela, E.V. (2012). Significance of tax exemptions and institutional factors in stimulating investment. (pp. 25-28). Tax policy and practice. №3-1.

Rodionov, I.I. \& Pashkov, N.A. (2012). Debt financing for medium-sized Russian companies: the possibility of bond market. (pp. 43-54). Corporate Finance. №2 (22).

Kheifetz, B. Risks of Russia's debt policy against the background of the global debt crisis. (pp. 80-97). Questions of economy. №3.

Aliev, B.Kh.(2000). Industrial policy and economy. M .: Economics. 104 p.

Tatuev, A.A. (2014). The factors of Russian industrial sector sustainable development. (pp. 30-33). Economy and entrepreneurship. № 11-4 (52-4).

Andrianov. K.N. (2013). Evolution and strategies of state industrial policy. (pp. 48-54). Industrial Policy in the Russian Federation. №7-9.

Romanova, O.A. \& Bukhvalov, N.Y. (2014). Theoretical foundations as the platform of industrial policy system during the new industrialization. (pp. 53-66). Economic and social changes: facts, trends, forecast. №2 (32).

Kuzmina, Yu. (2011). Cluster policy: the benefits of innovative clusters. (pp. 219-224). Problems of modern economy (Novossibirsk). №4-1.

Borodin, A.I., Tatuev, A.A., Shash, N.N., Lyapuntsova, E.V., Rokotyanskaya, V.V. (2015). Economic-mathematical model of building a companies potential. (pp. 198-205). Asian Social Science. Vol. 11, № 14. 